not placed on big boards, but in specialized journals, which are bought by people with an abundance above average, negative resonance could not be.

Thus, organizers of advertising should take into consideration that in addition to commercial, it also has a social effect, scandalous, shocking, unethical advertising can bring not only positive but also negative results.

DOI: http://doi.org/10.31617/k.knute.2019-03-19.06

\title{
THE PROBLEM OF SOFTWARE PIRACY
}

\author{
Lizunova E. \\ student \\ Saxion Colleges, Netherlends
}

Keywords: image, software products.

Today at the stage of formation and active development of the media industry, various difficulties arise. These figures can not be explained only by the «underdevelopment» of the market and the general economic problems of the state. You can talk about a number of difficulties faced by, for example, software manufacturers. In particular, the problem of software piracy is more urgent than ever. According to the BSA, $86 \%$ of software products in the world are currently distributed illegally.

If, at the beginning of the development of information industries, piracy was the factor that did not allow the consumer to keep up with modern technologies at the time, then at present it has become a hindering factor that seriously hinders the development of software manufacturers.

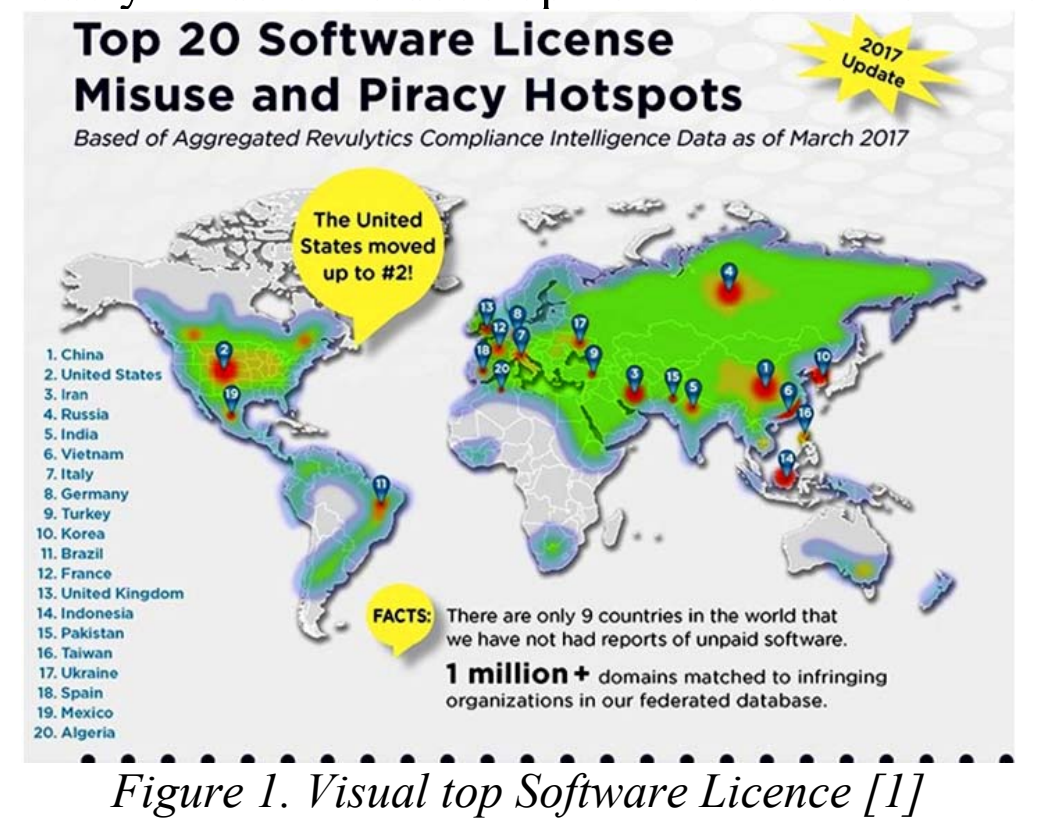


BSA | The Software Alliance recently released its 2018 Global Software Survey and I thought it would be useful to review some of the findings and their implications for software vendors and end user organizations.

The commercial value of unlicensed software globally is $\$ 46.3$ billion, and $37 \%$ of software installed on personal computers is unlicensed.

While these numbers are down slightly from the 2016 Global Software Survey, they underscore the fact that the use of unlicensed software is still widespread and carries a significant economic impact for both software vendors and their customers.

The commercial value of unlicensed software in North America and Western Europe alone is $\$ 19$ billion.

The interesting takeaway here is that this number represents $41 \%$ of the global number despite these regions having lower than average piracy rates (16\% and 26\% respectively). On its face this might seem troubling, but it is actually good news for software vendors looking to generate revenue from the use of unlicensed software using solutions like our Revulytics Compliance Intelligence. Not only do these regions have strong IP protection, our customers see high rates of converting unlicensed use through an inside sales approach that seeks to make infringers long term customers instead of treating them punitively [1].

\section{Piracy Adoption Trends from Revulytics Data Optimizer}

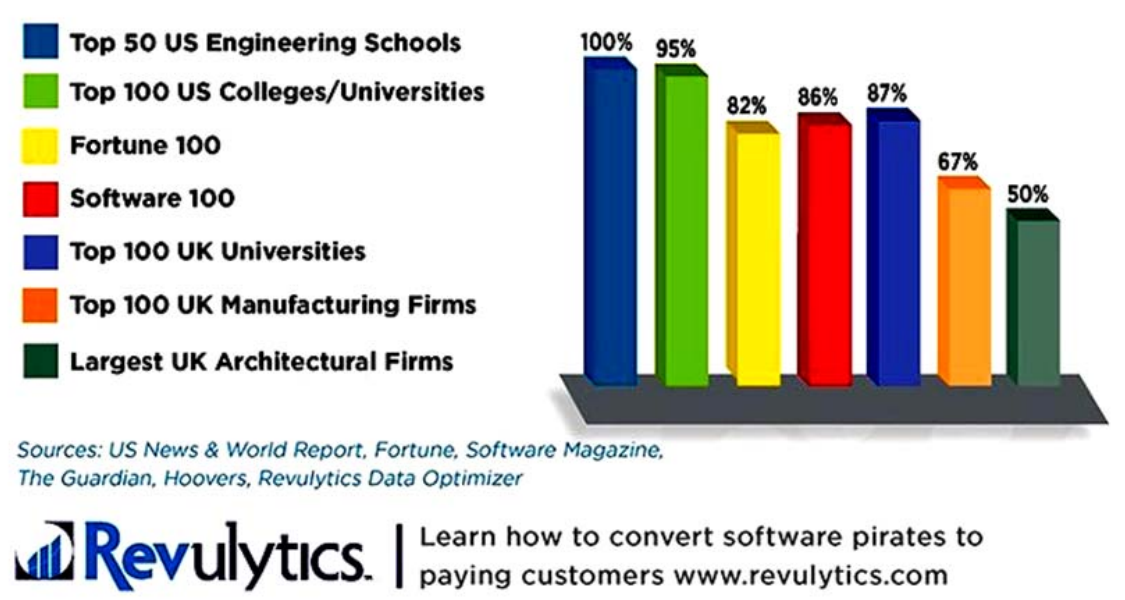

Figure 2. Piracy Adoption Trend [1]

Problems hindering the development of national software developers can be characterized by one phase - the absence of a civilized software market. This problem includes both the flaws in the legislation and the nonfunctioning protection mechanisms of domestic software manufacturers. 


\title{
References
}

1. Revulytics-software-piracy-statistics [Електронний ресурс]. - Mode of access : https://www.revulytics.com/blog/2018-revulytics-softwarepiracy-statistics - Title from the screen.

DOI: http://doi.org/10.31617/k.knute.2019-03-19.07

\section{THE ROLE OF ADVERTISEMENTS IN COSMETIC PRODUCTS PROMOTION}

\author{
Marenych V. \\ Candidate of sciences (Ph.D.), Senior Lecturer \\ Department of Journalism and Advertising \\ Kyiv National University of Trade and Economics, Ukraine \\ Koralewski J. \\ coordinator of international relations \\ Academy of Health, Beauty and Education, Poland
}

Keywords: consumer, advertising business, cosmetic products, cosmetics advertising, advertising in the media, art.

Cosmetics advertising is one of the most luxurious, beautiful and breathtaking attention, that is called the high qualities of cosmetic products, which prolong youth and beauty. For a specialist in advertising, creating an advertisement for cosmetics is unlimited possibilities for creating an image, associations with the advertised product. In cosmetics advertising there are no limites by signs: the impossibility of using any images, advertising face, ideas. However, in advertising, work professionals, and they do not allow themselves to make occasional decisions. Using marketing communications, methods for promoting the product, the advertising specialist can creatively approach the advertising of cosmetics, creating for each product its image, individuality.

Recently, advertising for cosmetics often uses celebrities to promote products. This is explained by the fact that the main consumers of cosmetics are women, and for them is very important authority and imitation, however, the advertising of cosmetics for men is also often replete with celebrities of cinema and pop. They associate themselves with celebrities and their lifestyle through the use of cosmetics and fragrances (perfumes). Advertising, which promotes cosmetics by the stars of cinema and show business, suggests that this or that product is offered for «star advice» that he uses in life. It's like a secret or a way to achieve success in life, a relationship between your lifestyle and the style of life of a star. But this does not mean that all stars promoting 